\title{
CLEMENTE RAUL EINSIEDEL - EIN BEITRAG ZUR DEUTSCH-BRASILIANISCHEN LITERATUR
}

\author{
REINALDO BOSSMANN
}

CLEMENTE RAUL EINSIEDEL is $\uparrow$ Paranaenser. Er wurde am 16. Juni 1905 in Curitiba geboren, wo sein Vater als Kunst-und Dekorationsmaler tätig war. In diesem Beruf war Johannes Clemens Einsiedel gezwungen, häufig seinen Wohnort zu wechseln, so auch nach Rio Claro, im Staate São Paulo. Im Alter von 6 Jahren ist der junge Einsiedel in Aue, in Sachsen. Er besucht dort die Bürgerschule, später die Realschule. Er entschliesst sich für den Gärtnerberuf und geht 1919 zu seinem Onkel Friedrich Koelbel, der in Davenhof, im Holsteinischen, Besitzer von Rosen-und Baumschulen ist. Nach dreijähriger Lehrzeit und dem Besuch der Fortbildungsschule arbeitet er als Gärtnergehilfe bei verschiedenen Firmen in Deutschland. Von $1929 \mathrm{ab}$ ist er, wissenhungrig und bestrebt, Neues hinzuzulernen, zur weiteren Ausbildung im Staatlichen Botanischen Garten von Berlin-Dahlem.

Mit der Machtergreifung der Nationalsozialisten wird er entlassen und kommt in das Heer der Arbeitslosen. Um nicht weiter Schuldner des Staates, von der Wohlfahrtsunterstützung dürftig lebend, zu bleiben, kehrt er nach Aue zurück, wo man seine Kenntnisse für die Erstellung von neuen Grünanlagen gut verwenden kann. Ende 1934 heiratet er, kündigt den Dienst bei der städtischen Verwaltung in Aue, und, nachdem alles, was Geld bringen konnte, verkauft war, verlässt er Deutschland mit seiner jungen Frau Johanna Irma, geb. Söllner, um in Brasilien, in Curitiba, ein neues Leben aufzubaven. Verschiedene Versuche, hier selbständig in seinem erlernten Beruf zu arbeiten, scheitern eben an den dazu fehlenden Mitteln und an portugiesischen Sprachkenntnissen. Er findet Arbeif bei der Companhia Telefônica Paranaense 1); später nach Castro versetzt, wird er dort Leiter der Telephonzentrale, erwirbt sich, neben Ansehen seiner Mitbürger, Verdienste um das Telephonwesen dieser Stadt und geht nach fünfunddreissigiähriger Tätigkeit 1970 in Ruhestand.

Clemente Raul Einsiedel pflegt und bebaut seinen Garten in

I) später Companhia Tolefónica Nacianal, dann Telepar. 
Castro, widmet sich seiner Familie, der Malerei $\left.{ }^{2}\right)$ und Poesie. Sein Vater soll ein blendender Erzähler gewesen sein, seine Mutter schrieb, in der Not und aus der Not, Artikel für Tageszeitungen und versuchte sich auch in Gedichten.

Einsiedel ist ein Kind seiner Zeit, geprägt durch den 1. Weltkrieg, durch die schweren Nachkriegsjahre und die Arbeitslosigkeit in Deutschland. Sein Weltbild ist ein kritisch-bejahendes. Ohne den schöpferischen Drang in der Kunst gibt es für ihn kein Leben. Am Pathos Schillers konnte er sich in der Schule begeistern, die ruhige ausgewogene Abgeklärtheit Goethes sprach den Erwachsenen an, die einfachen Lieder Löns nimmt der reife Mann gern auf, und die bitterwahre Ironie Tucholskys spricht ihn im Alter an, im Rückblick auf sein Leben. Er hat keinen ausgesprochenen Lieblingsdichter; bei jedem sucht er nach etwas Neuem, um sich daran zu erfreven und daraus zu lernen.

Schon als Jugendlicher schreibt Einsiedel die ersten Gedichte. Sie sind stark gefühlsbetont, Ausdruck des Spontanen, Reflexe von Gemütsbewegungen, von aus der Umwelt empfangenen Eindrücken, die sein Inneres bedrängten. Es sind Frühgedichte, die die Natur, die erste Liebe, Glück, Leid, Sehnsucht, die oft unerfüllte, und Träume besingen.

Sie alle sind durchweg romantisch überhaucht, oft von Melancholie, aber auch von Freude.

\section{Andacht}

Ringsum breiten sich die Berge in des Waldes grüner Pracht, Allmacht taucht jetzt ihre Werke in der Sonne gold'ner Pracht.

Und es ist, als ob die Sonne aller Schönheit dankbar lacht; mich durchrieselt ihre Wonne voll von Freude und Andacht.

Doch des Waldes Einsamkeit

bleibt in mir zurück.

alles Sehnen, alles Leid und ein Hang nach Glück.

2) Mit zwei Ausstellungen trat er Ende 1950 zur Jahthundersfeicr Castros an die Offentlichkeit. 
Übervoll ist mir der Tag.

Und die Blätter zittern leise, was ich denke, was ich sag', tönt als traute Waldesweise.

So versunken wie der Wald bin ich glückesbar, und mein Sehnen wünscht sich bald:

Sei mir offenbar!

\section{Daheim}

Über frisches Ackerland bin ich in den Tag gegangen, sitze nun am Waldesrand zwischen Sehnsucht und Verlangen.

Ringsum knospen alle Triebe, teilnahmsvoll mein Herze schlägt.

Überall ist Lenz und Liebe die nun neve Blüten trägt. Heimatlich grünen die Hänge, Vogelstimmen zwitschern süss, und die allbekannten Klänge sind der Seele Paradies.

\section{Frühlingsnacht}

Ein stilles Lied durchzieht die Bäume voll Duft und süsser Träume der Frühlingsnacht.

Und es klingt so innig und hallt so weit wie das Rauschen der Allmacht zur Ewigkeit.

\section{Abend}

Abendstille überall in geheimnisvoller Tiefe... Mir ist's, als ob's mich riefe zu dir...<smiles>[CH]1[CH]CC1</smiles>

Sollten Mächte versagen, Mächte klagen 
in stillem Graven...

Der Wille zum Leben

ist uns gegeben,

Leben zu schauen...

Fesseln springen

in hellem Klingen.

Seid unverzagt!

Der Morgen, er graut,

der Sonne Braut,

das Glück, es tagt.

\section{Geständnis}

Seh' innig in die Augen mir, ich will die Hand dir geben und will dein Freund, Begleiter sein, das Glück in deinem Leben

Noch mehr, ich will dein Wesen afmen wie gleiches Fleisch und Blut, damit sich unsre Herzen einen zu einem einz'gen Gut.

Ich will in deine Augen sehen in unverzagtem Blick und halten dann in meiner Hand das ganze Lebensglück.

$$
.1
$$

Nacht ist um mich. Wo ich gehe ist mein Denken nur bei dir. All' dein Lieben, deine Nähe spür' ich schmerzerfüllt in mir.

Deine Augen seh' ich trunken, deinen Körper hold und schlank, sehnend still, in mich versunken, und ich bin nach dir ganz krank.

Weisst du, Liebste, meinem Herzen bist du Sonne, Glück allein, und ich fühle tausend Schmerzen... Du, sei immer, immer mein! 


\section{Mutter}

In dir liegt die Wahrheit, du bist Mutter der Natur, des Schaffens Innigkeit, in dir ist Liebe nur.

Weib ist dein vergänglich Ich und Muttersein dein Leben, und alles, was durchströmet dich, heisst opfern, Leben geben.

Lass' noch die unerfüllte Sehnsucht warten! Noch glüht das Rot auf uns'ren Wangen, noch ist die Welt ein Blütengarten, kann stillen das Verlangen.

Noch kann die Jugend mit uns tollen, die junge Frucht reif werden. Noch kann uns aus dem Übervollen ein Glück ersteh'n auf Erden.

Und sollte das Schicksal dies nicht geben, das Glück im Sturm vertreiben, wird doch die Liebe unsrem Leben und ihre Sehnsucht bleiben.

Die späteren Gedichte Einsiedels sind kritischer, bedächtiger, Rückblicke aus der Sicht des Alternden, nehmen zu Zeitströmungen Stellung und sind voller Gottvertrauen, Gott als Lenker aller Geschicke:

O könnte meine Sehnsucht klagen, erdichten aus dem Urgefühl, was ich in Worten möchte sagen, die rauh verklingen, herb und kühl.

O könnt' ich jenem Ausdruck geben, das mich beschwingt, das mich erfüllt, das Seltsam, könnte ich ihm leben, das Ruhelose in mir stillt.

\section{Irgendwo}

Irgendwo fällt dein Schatten, irgendwo bleibt dein Geist haften, 
irgendwo, ungesehen, unbewusst und ungeliebt.

Einmal wirst du denken, einmal rasten,

wenn dein Schatten sich vor deine Augen schiebt, und in deinen Ohren wird noch hallen

deiner Jugend Schritt,

und zu deinem Schatten wirst du lallen:

Gehe mit, gehe mit!

Einmal wirst du sehen

an einem Ort der Wiederkehr, irgendwo! Du wirst schweigen, zu bewusst und unverstanden, wenn die Heimat ist der Freude leer.

Und in deinen Sinnen wird noch spielen, wehmütig, doch froh,

alles, was die Welt in deinen Jugendzielen

dir verhiess - irgendwo!

\section{Neuzeit}

Es ist dunkel in unserer Seele, dunkel sind die Gedanken, die nach Klarheit suchen, einer Klarheit, einer Wahrheit.

Aber wir stossen uns an allem, an dem Realen des Geistes, an der Oberflächlichkeit der Sinne, im Denken, im Versenken.

Keine Ideale gibt es mehr?

Nur das Horten von Werten, das ewige Hasten

im Vermehren, im Verzehren?

Keine Zeit mehr für traute Worte, keinen Sinn mehr für das Schöne?

Nur schüchterne Blicke

voller Schmerz ohne Herz?

\section{Tradition}

Wir alle wissen was Tradition.

Für viele ist sie vergessen schon

und tragen sie wie eine Bürde.

Wer sie verleugnet, verliert Würde. 
Nun legt sie ab! Befreit den Geist vom Herkommen, der uns beweist, dass unser Sein steht mit den Alten, gezeugt, erworben zu behalten. Denn sie ist heilig. Es ist Lüge, dass uns die Tradition betrüge.

Das Elternhaus, das Vaterland ist Tradition aus erster Hand wie unser Glaube, Sprache, Sitte nicht zu verleugnen ist, ich bitte... Was ist denn das Moderne schon? Die Wahrheit lebt aus Tradition.

$$
.1
$$

Sie haben alle gestritten um Gott, sie haben alle gelitten um Gott, sie haben alle geglaubt und gesehnt, sie haben alle geirrt und gewähnt das Unmögliche, das Unselige geträumt, die menschliche Liebe, das Wahre versäumt, die Untat als Freude gewahrt, den Glauben als Gottheit genarrt.

\section{Abhängig}

Ich lerne fügen mich der Allmacht und bete täglich zu den Sternen, zu einem Gott in weiten Fernen und suche Licht in meiner Nacht.

Ich lerne sehen tausend neve Sachen und flehe täglich zu der Kraft, die alles Werden wirklich schafft, mit Freude und der Kunst zu lachen.

Ich lerne beten für die Seelengüter um einen Trost, der mit Vernunft mich ganz erfüllt in einer Wiederkunft, im trauten Ton der Heimatlieder.

Seine Verse offenbaren verständnisvolles Empfinden und Verbundenheit zu der Blütenpracht der Natur. 


\section{Blume}

So zart bist du, so schön

wie Gold der Sonne,

das sich blendend bricht,

kaum zu berühren.

Meine Hände formen sich,

möchten dich heben

zum Licht.

Zarte Blume, schön wie das Glück,

das Schmerz und Leid geboren,

wie ein Hauch, wie ein Kuss.

Ich sehe dich, spüre dich, doch bist du mir verloren.

In dem vor uns liegenden Manuskript "), mit ungefähr 400 Gedichten, die Einsiedel DES LEBENS JAHRESZEITEN nennt, stellt er den Menschen in den ewigen Lauf der Jahreszeiten als ihren ständigen Begleiter. Einsiedel ist konservativer Denkungsart, doch den gegenwärtigen Zeiterscheinungen nicht ganz verschlossen - er belächelt sie als unausbleibliche und notwendige Ubel, mit denen man leben und sich auseinander setzen muss. Als Gedichttitel kommen deshalb sehr oft die traditionellen Werte vor wie Recht, Glaube, Ehre, Würde. Viele seiner Verse sind erfüllt von der Sehnsucht nach der deutschen Landschaft mit ihren Wäldern, Flüssen, Tälern und Höhenzügen. In einigen Gedichten hat er es verstanden, die Landschaft Paranás nachzuempfinden, das Charakteristische an Menschen und ihrem Tun im Tagesablauf zu zeichnen:

Wenn der Abend erst die Kühle in Nebeln von den Bergen bringt und die ganze Tropenschwüle mit frischem Tau durchdringt, wenn die Trägheit der Bewegung sich mit losem Rhythmus hebt, dann erst kommt die frohe Stunde, in der ein Europäer lebt.

Und er lauscht in seinem Innern, von dem fremden Ton umgeben, nach den Klängen kühler Zonen und der Heimat fernem Leben.

3) Koines dieser Gedichte wurde bisher veröffentlicht. Er schrieb sie für sich, nicht zur Veröffentlichung, als spontanen Ausdruck des Empfindens. 
Fremde Lieder der Gitarre

monoton sein Haus umwallen, und er sehnt sich nach den Klängen,

Orgeln grosser Kirchenhallen, nach dem Rauschen seines Waldes, da tief atmet seine Brust, und sich seine Glieder dehnen in freier, körperlicher Lust. $\left.{ }^{4}\right)$

\section{Antonina}

Sonntag in der kleinen Stadt. Palmen ragen stolz am Hafen, der so wenig Schiffe hat, und alles ruht still, müd' zum Schlafen.

Träge schlürfen die Mulatten ihren Chimarrão der Runde, spucken dann den grünen Speichel saftig aus dem vollen Munde.

Müde hockt der Polizist, stiert und bläkt die weissen Zähne; ob es ihm gestattet ist, dass er selbst im Dienst auch gähne?

Grell scheint bloss die heisse Sonne auf die groben Pflastersteine, keinen Schatten wirft die Tanne auf die dunkelbraunen Beine. Jeder harrt in paciência, träumt in diesem Einerlei, und wer kommt, haucht com licença, setzł sich rauchend mit dabei.

Träge in den schwülen Lüften hebt das Meer sich mit der Flut, saugen in den Mangodüften sich Moskiten voll mit Blut.

Kurzes Dämmern zeigt das Scheiden eines heissen Tages an; doch nun fängt in diesen Breiten erst das rich'tge Leben an.

4) Geschrieben in Antonina, Parand, im Jahre 1939. 
Bumla, bumla summen cantos,

Klagelieder der caboclos

quellen aus den alten ranchos,

Duft von café und cigarros.

Kinder lärmen auf den Gassen, Grillen zirpen, Frösche quaken, und bevölkert sind die Strassen von dem trägen, müden Schnaken.

An dem Kai gluckst schwer das Meer, blinkt ein Himmel voller Sterne, und kein Wind bringt Kühlung her aus dem Dunkel weiter Ferne.

Dass Einsiedel auch gesunden Humor hat, zeigen die folgenden Verse auf:
Gestern sprang des Müllers Liese leichtfüssig übern Bach.
Sie fiel hinein. Wie es geschah, weiss keiner. Aber ach!
Der Schuster Heinz, der Schuster Kurt, sie sehen lachend zu. Ich eilte schnell gefasst herbei und zog sie raus im Nu.
Und führte sie, so nass sie war, dort auf die sonn'ge Wiese.
Was glaubt ihr wohl, ihr Schusterjungs? Ich sah, wie schön die Liese.

Unser Freund aus Castro, ein kritischer Betrachter mancher für ihn negativer Zeitströmungen, ein Betrachter, der liebend blickt und die Umwelt gar zu gern mit dem Etikett "in Ordnung" versehen möchte, gibt den Mitmenschen einen positiven Wegweiser in dem 1968 geschriebenen Gedicht:

Viel Schönes gibt es auf der Welt, wenn sie ein Sonnenstrahl erhellt, wenn alles ist voll Harmonie in jeder Seele, aber wie? 
Heirate, hilf den Weg zu gehen

und bleibe nicht gelangweilt stehen!

Viel besser geht es sich zu zwei'n,

auch soll dabei Vertrauen sein.

Der Weg ist lang; ihn zu beschreiten

erfordert Liebe, auch Bescheiden.

Erscheint der Pfad auch oft zu schmal,

vergesse nie den Sonnenstrahl!

\section{RESUMO}

Clemente Raul Einsiedel é paranaense, nascido a 16 de junho de 1905, em Curitiba, onde seu pai foi artista em pintura e decorações. Com seis anos de idade, o menino Raul está em Aue, na Alemanha, fazendo lá o curso primário e, mais tarde frequenta a escola secundária. Decide-se para a profissão de jardineiro. Após a aprendizagem de três anos e a conclusão da escola profissional, Raul trabalha como jardineiro em diversas firmas na Alemanha. A partir de 1929, ávido de saber e para estar sempre atualizado em atividades profissionais, escolhe o Jardim Botânico Estadual de BerlimDahlem como campo de seu aperfeiçoamento. Com a ascenção ao poder do nacional-socialismo, perde o emprego, volta a Aue, onde serão aproveitados seus conhecimentos pela administração municipal na criação de novos parques e jardins. Pelos fins de 1934, casa-se e volta para sua terra natal. Tentativas de trabalhar em Curitiba, co. mo jardineiro independente, fracassam devido à falta de recursos financeiros. Emprega-se na então Companhia Telefônica Paranaense; depois transferido para Castro, trabalha como gerente da central telefônica. E, após trinta e cinco anos de serviço, aposenta-se, em 1970.

Ainda jovem, escreve os primeiros versos, dando expressão poética às emoções causadas pelo ambiente, poemas que qualificamos de românticos. Sua visão do mundo é crítico-positiva. Sem o ímpeto criador na arte, para ele não existe vida nenhuma. Sendo de mentalidade conservadora, acentua na lírica os antigos valores da humanidade, como justiça, fé, dignidade, honra e tradição, conceitos que se acham muitas vêzes nos títulos de seus poemas. As tendências do nosso tempo e a vida considera como males inevitáveis e necessários, com os quais o homem deve conviver e diante deles tomar posição. Einsiedel escreveu um ciclo de poesias, cêrca de 400 , com - título de "Estações da vida", colocando, assim, o homem no decurso eterno das estações do ano, como seu companheiro. Muitos 
versos de nosso amigo, ainda não publicados, refletem a natureza, as saudades das paisagens alemãs, suas florestas, rios, vales e montanhas. Alguns lembram o ambiente paranaense, as características da nafureza e do homem com afazeres diários.

\section{- literatura}

\section{Novidades do autores do língua alemá}

Diefer Wellershoff, autor de "Schathengrenze" (Limite da Sombra, vejam-se as Noticias Culturais da Alemanha de Maio de 1969), acabo de fublicar "ensaios para uma metacrítica da literatura" sob o título "Literatur und Verānderung" (Literatura e Transfor. maşōo, Colónia 1969, 188 p.). As reflexōes de Wellershoff sāo expressōo de uma insegurança geral; defende uma literatura de ficçāo e do âmbito particular: "Nunca consegui compreender que literatura como liferatura seja um valor. Também não a sua mera interpretação imanente e o culto da obra de arte perfeita em si e autónoma...". E surprecndente que neste notável ensaio de teoria li:erária o autor quase não analisa as formas da expressão linguística: "A língua nāo pcde concorrer com as sugestōes sensoriais do filme, o envolvimento do beat, os apelos cróticos da moda e é cada vez menos convincente que $o$ individuo se retraia antes estas ofertas para os mundos fictícios do literatura, iransmitidos por simibolos".

O autor de 27 anos Gïnter Wallraff, residente em Colónia, publicou sob o título "13 unerwünschte Reportagen" (13 reportagens indesejadas, Colónia 1969, 212 p.). A diferença do reporter tradicional que se aproxima do seu objecto do exterior, Wallraff coligiu moterial no qual êle próprio desempenhou diferentes papéis na sociedade: como operário pago por tarefa e trabalhando junto à faixa, como vagabundo num asilo, como alcó́lico numa clínica, como fabricante de Napalm ou como esbirro poli. tico. Estas reportagens säo compactas, informativas, coerentes e convincentes; mas sāo escritas "sem qualquer refinamento da exposiçāo e da documentação; náa contẻm conclusōes que, numa atifude analítica e de teoria social, conduzam para além de cada caso e dos factos com ếe relacionados" (Siegfried Schcber).

As duas obras sairom na nova série da Editôra Kiepenhever \& Witsch "pocket", na qual se tenciona apresentar anualmente quinze a vintc títulos (romances, contos, ensaios, colagens de textos, estudos sôbre o cinema e o tcatro, análises e relatórios políficos).

Outro observador crílico do cenário alemāo é Horst Krüger, de 50 anos, que depois de ter exercido, durante muites anos, intensa alividade como redator na rádio, vive agora em Francfort como eseritor independente. Krüger publicou na Editora Piper o livro "Dcutsche Augenblicke" (Momentos alemães) ou, cama diz no subtílulo, "Bilder aus meinem Vaterland" (Quadros da minha pátria, Munique 1969, 318 p.). Trata-5e de uma coletânea de apontamentos de diário, esboços e quadros de viagem que figuram entre o mais importante "que se escreveu, sob um ponto de vista crítico, para bem da Alemanha de hoje" (Herbert Heckmann). Krüger colocou entre os seus textos trechas de "Deutschland, ein Wintermörthen" (A Alemanha, um conto de inverno) de Heinrich Heine. Esta intercalaçäo é mais da que um gesto literário: indico - tradição na qual o autor se situa. Os scus textos são obras mestras na arte da observaçäo e da comunicaçāo. 
Entre as novidades em discussão figura o primeiro romance de Wolfgang Georg Fischer, de 36 anos, "Wohnungen" (Moradias, Editora Hanser, Munique 1969, 207 p.), uma tentativa de representar as transformaçōes sociais mediante o exemplo de Vieno no: anos de 1910 a 1938. "O romance mostra o munda das coisas como reflexo do mundo das pessoas" (Helmut Mader). Fischer nasceu em Viena e vive em Londics. A Editora Hanser lançou ainda o romance "Hochzeit in Konstantinopel" (Casamento em Constantinopla, Munique, 249 p.) de Irmtraud Morgner. São excursóes numa realidade sonhada, fixada num diário fictício de uma lovem berlinense da parte oriental da cidade durante uma viagem de núpcias sem romantismo a uma fequena praia $\mathrm{nz}$ lugoslávia à qual a autora deu o nome de Constantinopla. A linguagem é simples, os períodos curtos, precisos, sendo, is vêzes, repetidos como se fosscm um leitmotiv. E também berlinense a autora do romance "Oktoberlich" (Luz do Outubro), Ingeborg Drewitz (Nymphenburger Verlagshandlung, Munique 1969, 174 p.). O leatro da açāo é Berlim; o destino da cidade dividida reflete-se na história de um casal divorciado Vários capítulcs representam duas correntes paralelas: a atualidade contada na primeira pessoa, as focagens do passado na terceira pessoa. Na pessoa do austríaco Michacl Scharang, nascido em 1941, a Editora Luchterhand apresenta um contista cuja obra "Verfahren eines Verfahrens" (Precesso de um processo, Editora Luchterhand, Neuwied 1969, 95 p.) consiste, em essĉncia, de experiênclas com a língua. O conto nāo decorre, como Helmul Heissenbüttel cscreve num posfácio, nos acontecimentos da uma realidade recordada ou imaginada, mas segue "movimentos, que decorrem na sintaxe e no campo de significado das palavras". Constitui um excmplo de poesia "concreta". - "Minimonsters Traumlexikon" (Dicionário de sonhos do Minimonstro, Editora Rowohlt, Hamburgo 1968, 94 p.) de Friederike Mayröcker. A autora vienense, nascida em 1924, constrai -um mundo de textcs "que pretende demonstrar-nos o contexto infinito, mas nāo contável, de lodas as palavras", escroveu Max Bense no pósfacio.

Depois de se ter cstreado com o romance "Ein ungeratener Sohn" lUm filho degane. rado), Renate Rasp apresenta-se como poctisa no volume "Eine Rennstrecke" (Um pcr. curso de corrida, Editora Kicpenhever \& Witsch, Colćnia 1969, 62 p.). O percurso de corrida que a autora percorre é marcado de imagens da perda da própria individualidade, da dissoluçāo c do estranhamento. "Vorgefundene Gedichte" (Poesias encontradas, Editora Hanser, Munique 1969, 48 p.) ć o fítulo que Horst Blenek deu à sua coletânea de textos montados, que pretendem desmoscarar costumes de leitura e da locuçāo. O material provćm de texios de propaganda, jornais, guias telefónicos, dicio. nários, slogans revolucionários, eic. Encontram-se os mais belos textos ondo Bienck vai para além de aquilo que encontrou. Rudalf Hagelstange designou de conto de primavera o seu livro poético-satírico "Der Krak in Prag" 10 polvo em Praga, Editora Hoffmann \& Campe, Hamburgo 1969, 57 p.). O poeta Hagclstange iranspôs a ocupaçāo militar de Praga na imagem de um polvo gigantesco cujos tentáculos se lançam sábre paises, cidades e homens.

\section{Liferalura do leste da Europo em traduçōes alemäs}

Por ocasiāo da inauguraçăo no dia 4 de Oufubro ,na Haia, da exposição itinerante "Literatura do leste da Europa em traduçóes alemās", organizada por Inter Nationes, falaram, entre outros oradores mais, o eslavista holandês Prof. Karel van het Reve, da Universidade do Leide, e o escritor alemsa e tradutor de literatura polonèsa Carl Dedecius. A exposiçāo, patenteada em seguida no Instituto Gocthe em Amesterdāo - Roterdão, abrange cêrca de 500 fífulos de traduções do sérvio-croata, do sloveno, 
do polonês, do rameno, do russo, do úngaro, do checo e do eslovaco. Depois da última estaçāo na Holanda, Nijmegen, a exposiçāo deve ser apresentada, em principios do ano vindouro, nas salas da Biblioteca Alemã em Bruxelas. Em cooperação com Inter Nationes, a Editora Vandenhoeck \& Ruprecht, em Gcettingen, lançou uma biblio. grafia "Literatura do leste da Europa em iraduçōes alemās", que abrange cêrca de 1.000 tífulos.

\section{Exposiģão comemorativa de Robert Musil}

Ao autor austríaco Robert Musil (1880-1942) dedicou-se uma exposiçāo no Oberrheıni. sches Dichtermuseum, em Karlsruhe, organizada pelo Arquivo Musil, em Klagenfurt. Entre os documentos referentes à vida, à obra e à importancia deste grande individualista, figuram numarosas cartas, manuscritos, fotografias e recensōes. $E$ altamente elucidativa a crítica em oito colunas, da autoria de Alfred Kerr, da primeira publicação de Musil "Die Verwirrungen des Zöglinas Törless" (As atrapalhaçóes do discípulo Törless), publicado cm 1906 ou a recensāo de Adolf Frisé do romance "Der Mann ohne Eigenschafien" (O homem sem qualidades), publicado em 1931. Este romance, que não passou de fragmento, é considerado hoje uma análise elarividente da cultura moderna e do sociedade no século $X X$.

\section{LITERATURA}

\section{Novidades de autores de língua aloma}

No seu romance "Maria Morzeck oder Das Kaninchen bin ich" (Maria Morseck ou O coelho sou eu, Editora Biederstein, Munique 1969, 312 Ppl, Monfred Biclęr oferece um exemplo da originalidade berlinense, dando provas de ser um autor "que no diálogo é capaz de evocar uma realidade humana e histórica" (Frankfurt Allgemeine Zeitung). Maria Morzeck, jovem berlinense do leste do cidade, escreve simplesmente “... o que eu própria vivi e de que não posso falar com ninguém...". A linguagem não est́́ vinculada a qualquer geraçāo ou a erisérios locais, mas à linguagem pes. soal, na qual so manifesta o inconfundivel de um carácter. $O$ autor de 35 onos, que cm 1968 veio da República Demecrática Alemă, via Praga, para o Sul da Alemanha, apresentou com éste livro a terceira feição de uma tragicomédia erótica que devia ser lançada em 1965 na República Democrática Alemã como filme e romance.

O nôvo romance de Peler Härtling "Das Familienfest oder Das Ende der Geschichte" (A festa de familia ou $O$ fim da história, Editora Henry Goverts, Estugarda 1969, 312 P.). publicado como última parte de uma trilogia, da qual já publicara "Niembsch" e "Janek", deu origem a uma controvérsia dos críticos. Cama já nos livros precedentes, - história decorre no século XIX; O autor mostra certa afinidade de idéias com o estilo da respectiva época. Neste esboço da história de uma família em Vurtemberga, em meados do século passado, o tema de Härtling é a cogniçāo subjectiva do mundo. "A orientação pelo Wassado nāo diminui, porém, a releváncia atual do seu trabalho" (Werner Schulze-Rcimpell). Para êle a histćrio é um tecido de momentos, vivèncias c recordaçōes - "Recordaçōes como rede lançada para captar realidades fugitivas" (Barbara Bondy). A composiçāo do romance é discontínua; monólogos, diálogos, re. latos e cartas, níveis temporais, níveis do visão: fudo muda constantemente, formando um emaranhado quase impossível de destrinçar. O livro notável de um autor "engagé", - que confirmam, näo por último, as numerosas recensōes "engagés". 
O. cditor berlinense Klaus Wagenbach lançou, em colaboraçāo com Michael Krüger, - segundo anuário de lircratura confemporânea "Tintenfisch 2" (Polvo 2). A opiniāo de Wogenbach que se devem procurar os acontecimentos essenciais da literatura na actualidade além do romance, na prosa breve ou na poesia, reverte em benefício desta antologia de autores do língua alemā. Wagenbach oferece so leitor exclusivamente textos sem cortes do ano de 1968 e, apesar da escassez do espaço, um número rclativamente elevado de autores de relevo. Deu a preferéncia aos autores "que entendem a sua produção como sendo política", conforme se diz no prefácio. A escala dos textos, ensiquecida por marginais polémicas, tais como excertos de jornais e citações de políticos, demonstra que o discurso, a reportagem e o ensaio serāo colocados em pé de igualdade com a poesia, o romance c o conto. Por um lado, portanto, artigos e discursos politicos de Hans Hagnus Enzensberger, Böll, Handke, Hartmut Lange ou Peter Bichsel, do outro lado Christian Enzensberger, Hartmut Lange ou Pefer Bichsel, do outro lado Christion Enzensberger, Günter Eich, Erich Fricd, Reinhard Letrau ou Christa Reinig. Uma bibliografia informa sôbre todos os livros de autores de lingua alemã publicados no ano de 1968.

A lista das novidades de prosa c poesia $\mathrm{cm}$ língua alemá é tăo extensa que só é possival apontar as obras mais discutidas: na Editora S. Fischer, Francfort, O estudante Jürgen Alberts, de 23 anos, publicou o seu primeiro romance intitulado "Nokasch u. a. Drei Romane für eine Person" (Nokasch e outros. Três romances para uma pessoa). Alberts trabalha sobretudo com materiais já existentes, fenómenos típicos do mundo de consumo e cenas da vida cotidiana. Outros debutantes sāo Uve Schmidt, que com - seu romance "Höchstens drei Minuten" (No máximo, três minutos), segundo declara a Editora März, exemplifica a "Geschichte einer humanistischen Pleite". (A história do uma bancarrota humanistical, Jürgen Ploog com o seu primciro trabalho em prosa de maior tomo "Coca-Cola.Hinterlond" (Hinterland da Coca-Cola, Editora Melzer), no qual estó cm foco o "processso da demolição de convençōes linguísticas".

De entre os jovens autores conhecidos, Rolf Dieter Brinkmann publicou na Editora März "Vorspannstücke und andere Prasa" (Peças de introduçāo e prosa vária), um livro de leitura camo corte transversal dos diferentes lipos de prosa do autor e 'Stereo.Texte", de Peter 0 . Chotjewitz, sob o título "Vom Leben und Lernen" (Da vida e do aprender). Um dos "prosadores mais fortes a mais originais entre os jovens autores alemāes" (Die Zeit), Ror Wolf, publicou sob o título "Danke schön. Nichts zu danken" (Muito obrigado. De nada) histórias dos últimos anos. Poro êste autor a linguagem, a fábula e as figuras nāo são nado de fixo, entrecruzando-se frequentemente várias fábulas. Heinz Piontek, mais conhecido como poeta, lançou na Editora Hoffmann \& Campo "Liebeserklärungen in Prosa" (Declaraçöes de amar cm prosa), 34 trabalhos literários dos últimos anos, em parte de carácter biográfico, em parte provenientes dos diários do autor. Faltam os limites fixos entre os sonhos a as realidades. Os rabalhos do vienense Konrad Bayer, nascida em 1932 e que se suicidou em 1964, tinham sido publicados póstumamente pela Editora Rowohlt. Como esta primeira edição estava esgotada, a editora resolveu publicar o mais importante trabalho de Bayer sob o tífulo "der sechste sinn" (o sexto sentido). A inquietação, a dúvida na língua como meia de comunicação prestável, que nos últimos anos assaltara Bayer, encontroram neste fragmento de romance, em grande parte autobiográfico, uma feição autèntica. 


\section{Noticias das editoras alemás}

Dezoito editoras alemās e clubes de livro uniram-se no segundo maior grupo editorial alemāo. Em primeiro lugar está o Grupo Bertelsmann. Fazem parte do nôvo grupo o Grupo Holtzbrinck, com as editoros S. Fiseher, G.B. Fischer, Fischer-Bücherei, Goverts, Steingrüben, Stahlberg, Wolfgang Krüger e Amadis, O Grupo Ecen cem as Editoras Econ, Marion von Schröder e Claassen, a Editora Droemer-Knaur e duas editoras de jornais. Além das editcras, integraram-se no grupo os clubes "Deutsche Buchge. meinschaft", "Deutscher Bücherbund", "Evangelische Buchgemeinde", "Deutsche Haus. bücherei" \& "Moderner Buchklub". Numa seç̧ão de "Revistas Especializadas" rcunir-se-āo tôdas as publicaçōes perí́dicas das emprêsas integrantes do grupo. Está cm projeto uma editora comum de livros de bolso e uma produção comum de dicioná. rios. Segundo uma declaração dos editores, "as várias editoras conservarāo o seu perfil, continuarão politicamente independentes e desenvolverăo as suas relaçōes internacicnais, promeverāo jovens autcres e apoiarāo o comércio livrciro por mais inıı ensas medidas de propaganda".

Até 14 de Novembro, a "Stiffung Buchkunst" (Fundação Arte do Livrol mantém pa. rente ao público, em Francfort, livros, quadros, calendários e gravuras da "Eremiten. Presse", publicados de 1949 até 1969. Fundada há vinte anos, a provìvelmente mais conhecida pequena editora alemā laņ̧ou cèrca de vinte títulos, volumes de poesia e prosa contemporáneas, assim como gravuras em pequenas tiragens impressas à mäo. Entre os autores da "Eremiten-Presse" figuram o musicólogo e sociólogo Thecdor $W$. Adorno, o catedrático de filologia clássica e de literatura Walter Jens, cs escritores Werner Helwig, Hans Bender, Ernst Mcister e outras mais. A editora transferiu-se de Francfort para Stierstadi, no Taunus. O vigésimo aniversário da fundaçāo da editora "não é apenas motivo de festividades, mas também significa um dever", declararam os proprietários da editora, Dieter Hülsmann e Friedolin Reske. A série "Broschur", iniciado êste ano, oferece ediçōes bibliófilas a preços acessiveis. Já sairam os primciros nove volumes, cada qual de trinta a cinquenta folhas e quatro gravuras, na maiaria a côrcs. De entre cs autores desta série cumpre destacar Peter. O Chotjewitz, Christa Reinig, Günter Seuren e Gabriele Wohmann, assim como os gravadores HAP Grieshaber, Antes e Günter Bruno Fuchs.

Contro de investigação do litoratura alemã no exilio

- Instituto Alemão da Universidade de Estccolmo vai ser centro de investigação da literatura alcmá no exilio. Esta resoluşäo foi tomado por cêrca de 70 germanistas, historiodares dz literatura, bibilotecários e escritorcs de catorze paises, que em setembro último sa reuniram em Estocolmo no primeiro simpósio internscienal sôbre a literatura alemā dos exilados do Terceiro Reich. Germanistas americanos tencionam publicar uma obra de vinte volumes sôbre a literatura alemā no exílio americano; a literatura sccundária será coligida no centro, tornando-se tôdas as fontes acessiveis. Uma das mais importantes sugestōes do simpósio foi que na República Federal da Alemanha s2 deviam piocurar mais dourorandos que se ocupern de problemas com a importâneis, a projeção e o conteúdo da literatura de exilio. Sob o pento de vista filológico, é de extraordinário interèsse como a actual lingua viva alemā se alterou, no seu estilo e na sua sintaxa, em relação à língua dos autores que ainda vivem no estrangeiro c continuam a escrever em alemāo.

Extrato do revisto "Noticias Alemēs", editado por Inter Nationes, Bonn. 